\title{
DEPOIS DO ESTADO-NAÇÃO: MIGRAÇÕES, SOBERANIA E DIREITOS NA AƯRORA DA CRISE SISTÊMICA
}

\author{
AFTER THE NATION-STATE: MIGRATIONS, SOVEREIGNTY AND \\ RIGHTS AT THE SYSTEMIC CRISIS EMERGENCE
}

Fatima Sabrina da Rosa

Doutoranda em Ciências Sociais (Universidade do Vale do Rio dos Sinos/Brasil). Professora de História e Sociologia na Rede Estadual de Educação do Rio Grande do Sul. E-mail:sabrinna.rosa@hotmail.com.
Damaris Bertuzzi Mestre em Ciências Sociais

(Universidade do Vale do Rio dos Sinos/Brasil).

Professora no Centro Superior de

Tecnologia (Bento Gonçalves/Brasil).

E-mail:profedamis@gmail.com. 


\section{RESUMO}

Este texto pretende discutir a relação entre migrações e a perda da soberania do estado-nação no contexto da última crise sistêmica que vem se desenvolvendo. Para tanto, utiliza como base e pano de fundo as noções de modern world-sistem de Wallerstein e de longue durée de Braudel, bem como localiza a discussão sobre o Estado na perspectiva de crise sistêmica, de Arrighi, e de pós-nacionalismo, de Appadurai. Nesse sentido, o texto é dividido em quatro partes: apresentação do problema; contexto da crise migratória e da emergência do estado-nação; crise do estado-nação moderno e, por fim, algumas considerações acerca dos efeitos dos fluxos migratórios e de capitais sobre as noções de soberania e territorialidade do Estado.

Palavras-chave: Estado-nação. Migrações. Soberania. Crise sistêmica.

\section{ABSTRACT}

This text intends to discuss the relationship between migrations and the nation-state sovereignty loss in the context of last systemic crisis that has been developing. For that, it uses the notions of Wallerstein about the modern world-system and Braudel's about the longue durée as background, as well as locating the discussion about the State in the Arrighi's perspective about the systemic crisis and Appadurai's about the post-nationalism. In this sense, the text is divided into four parts: the presentation of the problem; the migratory crisis context and the nation-state emergence; the crisis about the modern nation-state, and finally, some considerations about the effects of migratory flows and capital on the notions of state sovereignty and territoriality.

Keywords: Nation-state. Migrations. Sovereignty. Systemic crisis. 


\section{INTRODUÇÃO}

Em um dos cenários desenhados por Arrighi e Silver (2001), os imigrantes e as mulheres figuram como novos atores das mudanças nas estruturas sociais que estão por vir. Desse modo, Arrighi sugere que a consciência de uma classe trabalhadora universal passa por uma "racialização", modificando a noção de um operariado nacional como motor das mudanças sociais. No interior do questionamento de Arrighi, reside a constatação de que, nas últimas décadas, a potencialização dos fluxos de pessoas, capitais e bens culturais, no cruzamento de fronteiras, tem modificado as relações de negociação entre a sociedade-civil, cada vez menos homogênea, e o estado, cada vez mais transpassado por poderes e decisões transnacionais. Como produto e coadjuvante nos processos de transnacionalização, os fluxos migratórios trazem à tona a questão levantada por Arrighi e Wallerstein sobre qual é o atual papel do Estado-nação. Ao mesmo tempo em que as fronteiras geográficas e jurídicas aparecem borradas tanto por movimentos de pessoas quanto de empresas, demandas nacionalistas e xenofóbicas disputam territórios discursivos e geográficos com o entendimento do mundo como uma comunidade humana. Nesse sentido, cabe questionar quais serão as novas configurações territoriais e quem serão os atores.

Nesse período, em que se percebe um intenso e progressivo aumento do fluxo de pessoas sobre fronteiras nacionais, o status e a soberania do Estado-nação sinalizam uma reconfiguração que merece atenção. Desse modo, este ensaio volta-se para as perspectivas de alguns autores, que envolvem novas formas de governança, as quais apontam para uma possibilidade de regulação na questão migratória, haja vista que os estados-nação têm demonstrado dificuldade em manejar localmente o problema que se constitui como tendência global. Para tanto, mapeamos algumas visões sobre o Estado-nação em sua relação com as migrações, colocando-as em diálogo com as perspectivas de Arrighi sobre uma crise sistêmica do capitalismo, tendo como estruturantes as noções de sistema-mundo moderno e de longa duração.

Para realizar este trabalho, cabe retomar o entendimento do capitalismo como estrutura de longa duração, remetendo aos trabalhos de Braudel ${ }^{1}$. Como fundamental representante da Escola dos Annales, Fernand Braudel éconhecido por trazer para a ciência histórica a perspectiva de longa duração de determinadas estruturas. Ao observar formas de abordagem da ciência econômica, Braudel nota a importância do entendimento de contextos históricos a partir de uma dialética cíclica em que uma estrutura se estabelece e se mantém por um determinado tempo, necessitando de um grande período para se desenvolver. Braudel traz a perspectiva de longa duração como certa oposição à ideia do acontecimento histórico e argumenta

\footnotetext{
${ }^{1}$ BRAUDEL, Fernand. Histoire et Sciences sociales: La longue durée. In: Économies, Sociétés, Civilisations. Annales... 13, n. 4, 1958, p. 725-753.
} 
que, partindo deste último conceito, não é possível observar estruturas que se mantêm em determinadas sociedades por uma temporalidade relativamente longa.

Conforme o ponto de vista braudeliano, Arrighi (2001), no livro O longo século XX, organiza e apresenta o desenvolvimento do capitalismo (desde sua fase mercantil) em ciclos hegemônicos, nos quais uma potência político-econômica dominaria o funcionamento do fluxo de capitais nos demais territórios compreendidos por cada ciclo.

\begin{abstract}
Cada qual caracterizado por uma unidade fundamental do agente e estrutura primários dos processos de acumulação de capital em escala mundial: um ciclo genovês, do século XV ao início do século XVII; um ciclo holandês, do fim do século XVI até decorrida a maior parte do XVIII; um ciclo britânico, da segunda metade do século XVIII até o início do século XX; e um ciclo norte americano, iniciado no fim do século XIX e que prossegue na atual fase de expansão financeira (ARRIGHI, 1996, p. 06).
\end{abstract}

Ao todo, Arrighi identifica quatro ciclos de dominação hegemônica em que o capitalismo teria se desenvolvido demonstrando características diferentes em cada fase. O primeiro ciclo hegemônico é dominado pelas cidades italianas; o segundo, pela Holanda; o terceiro, pela Grã-Bretanha e o mais recente, pelos Estados Unidos. Todos esses ciclos formam parte da longa duração do capitalismo e, como é próprio da dialética cíclica herdeira de Braudel, cada ciclo se gestou em um período de crise, convivência e competição com a forma econômica precedente. Já na obra Caos e governabilidade, o autor busca por padrões de mudança sistêmica nas transições hegemônicas do passado dentro do atual sistema moderno, observando as reorganizações fundamentais do sistema. Para Arrighi (2001, p. 31),

Essas reorganizações ocorreram em períodos de transição hegemônica, definidos como momentos de mudança do agente principal dos processos mundiais de acumulação de capital e das estruturas político-econômicas em que tais processos estão inseridos.

Uma característica fundamental da mudança nesses ciclos é que, a cada sistema hegemônico que substitui o anterior, a abrangência territorial cresce, mas a vigência do ciclo tem uma duração menor. Nesse último ciclo, a hegemonia econômica e/ou política estadunidense tornou-se global, estendendo-se o máximo possível e apresentando dissensos num período breve. Assim, para o autor, a atual crise mundial do Estado-nação se insere no decorrer de um esgotamento do sistema hegemônico mais recente que vem se desenhando desde a década de 1970, mas ainda apresenta uma nebulosa sobre o futuro do próximo ciclo hegemônico e sobre o próprio capitalismo. Além disso, a abordagem adotada neste trabalho considera a perspectiva de outro autor, Imanuel Wallerstein, herdeiro direto da tradição de Braudel. Este autor anuncia o fim da hegemonia dos Estados Unidos da América e, principalmente, a desintegração do sistema capitalista. 
Dessa perspectiva, adentramos no período do caos total que sugere um novo sistema. Esse novo sistema, ainda desconhecido, não está avaliado para melhor ou pior que o atual.

O sistema-mundo moderno parte de um entendimento do contexto histórico das Ciências Sociais dos séculos XIX e XX, para a qual o Estado era a unidade fundamental de ordenamento cotidiano. Na análise de Wallerstein, os diferentes estados-nação cumprem determinadas funções num jogo que integra o globo. Desse modo, as esferas política, econômica e sociocultural agem e inter-relacionam-se simultaneamente, compondo o conjunto de elementos desse sistema e estabelecendo uma divisão territorial do trabalho que integra as diferentes regiões do globo. Assim, o sistema-mundo moderno opera realizando uma espécie de cartografia social que posiciona os estados-nação em níveis de centralidade e periferização. Nesse sentido, as nações do Atlântico Norte, conhecidas potências econômicas, figurariam como centro, enquanto os países do "Sul Global" exerceriam diferentes nivelamentos de periferia e semi-periferia.

A ênfase na durabilidade dos eventos e estruturas, herdada de Braudel, também é um elemento fundamental do pensamento de Wallerstein. Os autores atentam para as formas como eventos e estruturas surgiram, qual era o contexto de sua emergência, quais eram suas regras e como se encaminharam para a crise estrutural. Wallerstein nos mostra que o sistema-mundo se modifica constantemente e nos conduz à constatação de que o sistema-mundo moderno, hoje vigente, vive uma crise estrutural e estaria manifestando a última etapa de sua durabilidade. Apesar dessa constatação, não é possível fazer uma previsão objetiva do futuro, por este ser o resultado de infinitas ações e decisões tomadas em todo o globo.

Acredita-se que os conceitos de sistema-mundo moderno e longa duração possam ser importantes bases para compreender a atual situação dos estados-nação em sua relação com a chamada "crise migratória", que tem se apresentado como decorrência de processos políticos e econômicos de caráter transnacional. Como efeito e coadjuvante nesse processo, os fluxos migratórios estão em diálogo com o contexto mundial de organização do sistema capitalista e suas tensões com determinados tipos de governos e de condução da política a nível nacional e internacional. Os efeitos perversos da divisão do trabalho nesse sistema estão presentes nos motivos pelos quais os sujeitos migram, nos lugares que elegem como destino, na forma como se inserem no mercado de trabalho e na forma como são percebidos como "ameaças" aos direitos dos cidadãos dos países-destino, justamente por disputarem, com grande parte destes, os postos mais subalternos de trabalho.

A dificuldade que os estados-nação têm apresentado na forma de lidar com as grandes corporações econômicas aparece aqui alinhada à percepção do "perigo da crise migratória" como um possível efeito decorrente do contexto que Arrighi (2001) reconhece como uma crise sistêmica. Nesse sentido, organizamos este trabalho na tentativa de construir o cenário de formação e crise do Estado-nação e do sistema-mundo, relacionando-os com a questão das migrações em escala mundial. 


\section{CONTEXTO DA CRISE MIGRATÓRIA}

As migrações em massa são um fenômeno recente. Sabe-se que nossos ancestrais já eram povos que migravam muito antes de se reconhecerem como humanos e que os primeiros movimentos migratórios partiram do Continente Africano e do Oriente Médio, dispersando-se pelo restante dos continentes. Nesse período, as migrações eram inerentes ao modo de vida humano. Eram deslocamentos considerados "naturais" e esperados em função da necessidade de sobrevivência, porém, atualmente, tais deslocamentos têm ocorrido de forma intensa e numa amplitude incontrolável e irregular, sem planejamento de quem parte ou de quem recebe o migrante. O fenômeno da migração, nos últimos anos, se impõe como um dado que atravessa a contemporaneidade.

\footnotetext{
De acuerdo con el reporte de desarrollo humano (UNDP, 2009), al inicio del nuevo milenio hay flujos muy considerables entre las grandes regiones del mundo: la emigración desde Europa hacia Norteamérica y Asia es de unos 17 millones de personas; el flujo de migración es igual de fuerte desde América Latina hacia América del Norte (Estados Unidos y Canadá), pues suma casi 20 millones de personas; desde Asia hacia Europa, la migración es también de cifras muy altas (cerca de 16 millones de migrantes), igual que hacia América del Norte (10 millones de personas). Aparte de esto, hay un flujo de personas muy considerable desde África hacia Europa (7.3 millones) y hacia Asia (unos 3 millones) (PRIES, 2016 p. 107).
}

Vive-se um momento em que as relações, anteriormente endógenas das comunidades rurais ou pequenas cidades, são escassas e, em determinados contextos, impossíveis. A interconexão das diferentes localidades do globo colocou povos muito diferentes em contato, gerando efeitos benéficos como a possibilidade de visualizar e compartilhar o multiculturalismo, mas também dando lugar a choques culturais que alimentam ideologias puristas, as quais insistem na abstração da homogeneidade nacional. De outro modo, dentre os problemas decorrentes sobre o destino dos povos migrantes, identifica-se a alteração de sua identidade nos locais escolhidos para migrarem. No espiral dos conflitos culturais, alguns migrantes perdem seus referentes de pertença na mesma medida que outros os tornam ainda mais patentes, como medida de autodefesa. Em alguns casos, os processos de hibridação (GARCíA-CANCLINI, 2008) decorrentes das migrações permitem que migrantes se manejem em diferentes posições de sujeito, acionando os referentes culturais novos e antigos, dependendo da situação. Estes mesmos processos associados aos problemas econômicos e ligados ao mundo do trabalho tendem a desestabilizar as fronteiras políticas dos estados-nação, principalmente aqueles que recebem grande afluxo de pessoas.

Segundo Pries (2016), ao final da primeira década do século XXI, já havia 200 milhões de imigrantes internacionais. Se comparado ao volume registrado na década de 1960, o total de imigrantes cresceu mais 
de 150\%. Além da circulação de pessoas nas fronteiras internacionais, um aspecto fundamental ligado à imigração não-forçada é a quantidade considerável de capital que cruza fronteiras através de remessas realizadas pelos imigrantes aos seus países de origem: "Mientras que para 1995 se calculaban 58 billones de dólares como remesas laborales, esta cifra aumento casi 300\% para 2004, llegando a 160 billones de dólares y alcanzando casi los 414 billones de dólares en el año 2009" (PRIES, 2016, p. 106).

Apesar da dura realidade enfrentada pelos imigrantes, principalmente os classificados como refugiados, e da resistência dos estados que começa a se mostrar, as migrações em massa prenunciam uma longa duração, alimentadas pela desestabilização das funções de cada área geográfica no sistema-mundo.

Hobsbawm² aponta que um dos elementos que afeta as nações é a aceleração do processo migratório, com os efeitos dessa mobilidade tanto fronteiriça e temporária quanto as duradouras. Com deslocamentos forçados, os números dessa mobilidade atingem estatísticas recordes que afetam uma em cada cento e treze pessoas no mundo (ACNUR³, 20 de junho de 2016). Para os movimentos do final do século XX, Estados Unidos, Canadá e Austrália foram os países que receberam milhões de imigrantes provenientes de todas as partes do mundo. Atualmente, os países que mais acolheram migrantes e refugiados no mundo foram a Alemanha, os Estados Unidos e a Itália, conforme o relatório de tendências globais da ONU, quadro este que se modifica constantemente. De outro modo, na Europa, lugar das origens do nacionalismo onde, na modernidade, cresceram os Estados nacionais (supostamente homogêneos em termos de etnia), o problema dos conflitos em torno de uma identidade nacional tem sido mais patente. Com as migrações e as misturas étnicas, dessa vez mais visíveis, reatualiza-se a questão da xenofobia, a qual também é percebida nas bases do capitalismo, uma vez que nesses países o imigrante representa a principal força de trabalho precarizado. Nesse sentido, esses dois processos se retroalimentam, os imigrantes em situação de vulnerabilidade aceitam os empregos mais subalternos, por sua vez a "inferiorização" dos mesmos é reificada e justificada através do trabalho. De qualquer forma, as disputas pela identidade ou mesmo pelos postos precários de trabalho têm reconfigurado as relações das sociedades com o estado a que pertencem.

Para Hobsbawm (2007, p. 95), o processo que transformou camponeses em "franceses" e imigrantes em "cidadãos americanos" está sendo revertido e dissolve as grandes identidades, como a do Estadonacional, convertendo-as em identidades grupais autorreferentes ou mesmo em identidades particulares não-nacionais.

\footnotetext{
${ }^{2}$ Citado por Arrighi (2001).

${ }^{3}$ Alto Comissariado das Nações Unidas para os Refugiados
} 


\section{SURGIMENTO DO ESTADO-NAÇÃO}

Por todo o mundo, os estados-nacionais surgiram em momentos históricos diferentes, aproveitando-se de situações peculiares e recebendo influências múltiplas, internas e externas. Analogamente, suas funções se modificaram ao longo do processo histórico. O bem-estar econômico e social promovidos durante muito tempo pelo Estado e sua soberania sofreram inúmeras mudanças que repercutem até os dias atuais numa intensa transformação em seus paradigmas.

Após os arranjos associados ao acordo de paz de Westphalia, de 1648, o princípio embrionário de soberania territorial torna-se o conceito fundador do estado-nação, embora muitas outras concepções afetem sua subsequente capacidade cultural de se imaginar e criar sua própria narrativa. Incluem-se aí noç̃̃es sobre língua, origem comum, consanguinidade e várias outras concepç̃ões de etnia. Ainda assim, a base lógica política e jurídica fundamental do sistema de estados-nação é a soberania territorial, mesmo que compreendida de forma complexa e articulada de modo delicado em cenários pósimperiais específicos (APPADURAI, 1997, p. 33).

A formação e a estruturação do Estado-nacional ocorreram na Europa no final da era medieval, a partir do século XI, quando o revigoramento do comércio e das cidades deram origem a um novo grupo social, a burguesia. Entretanto, a existência de nobres com direito de cunhar sua própria moeda e de cobrar taxas de quem passasse por suas terras encarecia as mercadorias e prejudicava os negócios para a burguesia. Foi assim que a burguesia e a monarquia se aproximaram: a burguesia em busca de proteção e ajuda; a monarquia interessada nos impostos pagos pela burguesia. Nesse contexto, a nobreza também se aproximou do rei visando conseguir cargos na corte, ajuda no exército real e ajuda militar contra as revoltas camponesas. Os camponeses, por sua vez, também passaram a ver o rei como alguém capaz de protegê-los contra os abusos da nobreza.

O conceito de soberania foi de fato formulado na Europa ocidental, numa época em que as estruturas de Estado eram muito frágeis. Os Estados tinham burocracias pequenas e ineficazes, forças armadas insipientes e ainda tinham que lidar com todo tipo de autoridades locais e jurisdições sobrepostas. Foi somente com as chamadas novas monarquias, do final do século XV, que o estado passou a garantir alguma estabilidade interna (WALLERSTEIN, 2002, p. 94).

Aos poucos, o rei assumiu o papel de mediador entre os diferentes grupos sociais. Logo, pode-se dizer que a formação de um Estado-nacional deriva das primeiras insurreições entre membros das hierarquias burguesas e nobrezas que disputavam territórios. A partir dessas divergências, surgiriam instituições que atenderiam ao interesse dos grupos sociais dominantes. Era o estabelecimento do Estado e do controle da 
Nação. Inevitavelmente, essa formação demonstrou-se fragilizada pelas ações marcadas pela diferença nos interesses sociais e econômicos. O resultado das desigualdades originou as primeiras crises institucionais no instante em que os indivíduos subjugados pela estrutura formada se mobilizavam em prol dos seus direitos. Com a passagem de uma sociedade agrária para uma industrial, a partir do advento da Revolução Industrial, constituiu-se o chamado Estado do bem-estar. O avanço desse sistema, baseado na livre empresa e com participação do aparato estatal, evidenciou a distinção entre a sociedade e o Estado. Tal distinção demonstrou que esse sistema atuava reciprocamente, cada qual em seu lugar. O Estado proporcionava aos seus cidadãos os meios que lhe davam acesso à renda e ao trabalho. Assim, o Estado era legitimado e o sistema estabilizado.

Dessa forma, o Estado representava o poder e a dominação; tanto organizava o espaço das relações sociais quanto as dominava. A ideia de um Estado-nacional vinculava-se à necessidade de apoiar o soberano para a construção de um Estado fortalecido e competitivo, que estabelecesse fronteiras precisas a fim de instituir uma nação onde todos teriam a possibilidade de ter uma identidade própria e até mesmo peculiar. A princípio, para a sociedade europeia ocidental, a formação do Estado-nacional representava a ordem após a crise instaurada no final do sistema feudal.

De outro modo, ao final da Segunda Guerra Mundial, os projetos nacionais de desenvolvimento econômico eram retomados, não aos moldes do início dos estados-nacionais, mas com projetos capitalistas que priorizavam desenvolvimentos industriais, entre outros. Em uma economia estruturada, a atuação estatal garante aos seus cidadãos conquistas voltadas para várias esferas, principalmente para os serviços sociais que se tornam mais complexos, aperfeiçoando técnicas que atenderão às demandas sociais.

No período pós- segunda guerra mundial, verificou-se que nos países da Europa Ocidental, berço dos estados-nacionais, as despesas do Estado eram consideravelmente aumentadas em relação às suas receitas. O resultado disso foi uma crise gerada pela instabilidade econômica, social e política, impossibilitando a permanência da ação do Estado por ser inviável uma relação equilibrada de bem-estar entre a Sociedade (representando o mercado) e o Estado (representando o público) (BEAUD, 1987).

Segundo Weber (1996), o Estado era a única estrutura capaz de dar suporte para o desenvolvimento do capitalismo. Porém, com a nova fase dessa relação, foi determinado o seu desequilíbrio e, inevitavelmente, a crise econômica capitalista. Aliado a essa crise, aparece a incompatibilidade do Estado em manter seu papel assistencial e social.

$\mathrm{Na}$ interpretação de Wallerstein (2002), o Estado precisa assumir posição/lado no processo de acumulação nesse sistema e manter seu papel, ainda que seja através de intervenções, como taxações e cobranças de impostos, já que estas asseguram a sua manutenção e sobrevivência. Wallerstein, juntamente com outros autores, têm apresentado em estudos e proposições as contradições fundamentais do sistema 
atual, como a extensa divisão social do trabalho que separa e distribui, de forma desigual, os resultados entre centro e periferia, fazendo com que Estado e Mercado sejam desvinculados. As contradições que sinalizam a crise sugerem que esta pode desestruturar e desconstruir o sistema, possibilitando a construção de um sistema novo.

\section{NA AURORA DA CRISE, A SOBERANIA DOS ESTADOS EM QUESTÃO}

As análises de diferentes autores apontam para o atual contexto como a agudização de uma crise dos estados e do sistema econômico. Arrighi identifica o atual momento como uma crise sistêmica que sinaliza a mudança na centralidade hegemônica do território e do governo dos Estados Unidos para outra territorialidade ainda incerta. Em uma das proposições lançadas para antecipar o quadro de poder que virá depois da crise, Arrighi aponta que alguns indícios revelam que a centralidade hegemônica poderia estar se dirigindo para um grupo de poderes ligados às economias do Leste Asiático, as quais pertencem a territórios que não formam, propriamente, estados-nação, como o caso de Hong-Kong.

Para Bauman e Bordoni (2016), a crise atual não é temporária, mas sinal de uma mudança profunda que envolve todo o sistema social e econômico dentro de uma longa duração. Já Hobsbawm pressupõe que o Estado-nação será substituído como forma de governo, e que o atual contexto sinaliza essa falência. Wallerstein (2002) aponta para o fato de que tal crise talvez prenuncie o último suspiro do capitalismo como estrutura de longa duração, a qual viemos assistindo se reconfigurar e permanecer como organização econômica dos Estados desde a aurora do sistema moderno. Para o autor, essa crise é peculiar porque vem sinalizar o fim do sistema histórico, que tem vigorado desde a formação no período de descoberta e invasão dos territórios do chamado Novo Mundo, e que garantiu, por esses séculos, a vigência de um pacto interestados e entre estes e os capitalistas.

\footnotetext{
Contudo este sistema histórico, como qualquer outro, tem suas contradições, e quando elas atingem um certo ponto (ou, dito de outro modo, quando sua trajetória se afastou do equilíbrio), o funcionamento normal do sistema se torna impossível. O sistema alcança um ponto de bifurcação. Há muitos sinais de que hoje tenhamos chegado a este ponto (WALLERSTEIN, 2002, p. 109).
}

Na esteira de Wallerstein, parte significativa dos intelectuais que se dedicam a analisar o tempo presente tendem a corroborar a noção de que estamos passando por um momento de crise intensa, na qual

\footnotetext{
${ }^{4}$ Citado por Arrighi
} 
algo parece estar chegando ao fim e, nesse ínterim, a soberania nacional e o próprio Estado-nação aparecem ameaçados.

Como afirmam Bauman e Bordoni (2016), a noção de crise representa etimologicamente "espaço de julgar" e é ligada também ao termo "critério", que sinaliza uma classificação de coisas e marca, portanto, uma fase de transição. Dentro do vocabulário político, o termo tem sido utilizado para definir um impasse econômico, bem como a falácia da possibilidade de uma constante ameaça de crise econômica assolando o imaginário coletivo e servindo como justificativa tanto para recessões quanto para repressões e diminuição de gastos públicos com serviços sociais. Qualquer encurtamento da "mão esquerda do Estado", bem como qualquer endurecimento na segurança pública e nacional é facilmente justificado pelo "perigo da crise".

As crises econômicas marcaram o desenvolvimento do capitalismo, e conforme Arrighi (1995 e 2001), marcaram também a transição hegemônica entre poderes, bem como as transformações ulteriores do sistema-mundo. Cada crise apresentou aspectos diferentes: a transição que assistimos apresenta como característica específica a relação entre sua amplitude e sua (inversamente proporcional) durabilidade. Esta crise atinge uma parte maior do planeta e, portanto, é mais difícil de contê-la, como previa Arrighi. Cabe perguntar-se, inclusive, se a crise, que parece transferir para algum ponto ainda incerto a hegemonia dos Estados Unidos, não tende a ser mais duradoura que a própria era estadunidense de dominação, haja vista que o domínio desse país se consolida definitivamente no período imediatamente posterior à Segunda Guerra e, já na década de 1970, sinaliza um fluxo de estremecimento em que breves crises são seguidas e alternadas com relativas recuperações.

Se entendermos a atual situação dentro de um fluxo de crises que advém depois de um período de expansão, isto é, entendendo-a apenas como crise econômica e não como transição sistêmica, em termos de perdas sociais, o que diferencia as crises do pós-guerra da atual é que, naquele momento, o refúgio e a resolução para a economia se encontrava no estado, podendo o mesmo recuperar as condições dignas de vida com algumas medidas de corte keynesiano. A solução do estado de bem-estar-social foi ativada em dois momentos de crise aguda quando os países emergiam da guerra devastados.

Com efeito, as consequências do colapso estenderam até o limite o modelo póswestfaliano de Estado munido de soberania absoluta e indivisível sobre seu território e tudo o que ele continha, mesmo sob formas tão variadas quanto as economias: soviética, administrada pelo Estado; alemã, regulamentada pelo Estado; e norte-americana, estimulada pelo Estado" (BAUMAN; BORDONI, 2016, p. 17).

O Estado-nação pós-westfaliano sai da guerra reforçado e expandido, predisposto a proteger seus cidadãos, mesmo como medida de segurança nacional contra disputas internas. As soluções de concessão 
de direitos sociais apoiados na estatização da economia estiveram presentes mesmo em países que não sofreram devastação das Guerras, mas foram atingidos pela crise decorrente dela. Um exemplo disso é a forma como o Estado brasileiro, sob a mão de Getúlio Vargas, conduziu a economia e a política negociando com os setores mais baixos de forma a desestimular a organização popular e aplacar as ânsias do proletariado, as quais, supostamente, poderiam convergir para uma solução comunista, caso o Estado não se mostrasse interessado em negociar. Nos países europeus, no entanto, a solução intermitente da maior intervenção do Estado dura até os anos 1970, quando começam as inflações, e a fé na solução nacionalista começa a erodir. Como demonstram Bauman e Bordoni (2016), o Estado passa a ser visto por uma parcela da opinião pública como um obstáculo ao bem-estar, e o mercado, como a saída para a crise. Da mesma forma que o estado funcionou como alternativa por três décadas no pós-Segunda Guerra, o mercado também correspondeu às expectativas (para alguns setores) pelo mesmo período mostrando que, ao fim e ao cabo, o mercado voltado só ao lucro cria catástrofes econômicas e sociais. Nesse sentido, a crise atual significa a descrença nos dois tipos de procedimentos. Para esses autores, mesmo que se acreditasse que o Estado retomaria o crescimento, isso não seria possível porque ele não é hoje o que foi há cem anos atrás, nem o que esperava que se tornasse.

Para Bauman e Bordoni (2016, p. 25), o grande impasse atual se encontra no fato de que, na atual circunstância, é possível observar um "estatismo sem estado" atuando na regulação de questões sócioeconômicas.

Escondida por trás de uma massa cada vez mais confusa e impenetrável de burocracia, a "governança" gerencia a comunidade, que perdeu seu guardião estatal por uma delegação incoerente que resulta na ideia de 'falsa democracia' pois carece de ambas as condições que tornam o mandato democrático: direção e controle políticos.

Para estes autores, a crise do Estado se encontra em dois elementos principais: a incapacidade do Estado de tomar decisões no âmbito econômico em função do domínio dos interesses financeiros supranacionais e a consequente incapacidade de prover serviços sociais. Quando conseguem regular a atividade financeira internamente, deparam-se com a incapacidade de resolver, no mesmo âmbito, questões sociais produzidas em um contexto global, como é caso das migrações.

No atual contexto, os governos democráticos encontram-se presos a um duplo compromisso em que as demandas de cada lado não são conciliáveis. De um lado, está a pressão exercida pelos eleitores; de outro, as forças globalizadas que atuam no espaço de fluxos, tornando nula a regulamentação do Estado territorial.

A insegurança dos cidadãos frente à incapacidade dos governos de preverem e regulamentarem as ações do mercado acentua a percepção do caos. Nesse sentido, Bauman e Bordoni (2016 p. 34) apontam para uma crise do estado em termos de soberania territorial. 


\begin{abstract}
Tais unidades formalmente soberanas - com efeito, um número crescente delas - foram rebaixadas na prática à condição de distritos de polícia locais, em prontidão a fim de garantir um mínimo necessário de lei e ordem para um tráfego cujas idas e vindas elas não pretendem (nem são capazes de) controlar.
\end{abstract}

O tráfego ao qual os autores se referem está relacionado aos movimentos migratórios e mesmo à liberdade de fluxo de pessoas em termos de segurança pública. No entanto, segundo Wallerstein (2002), o fluxo para o qual o estado está disposto a garantir a segurança não é de pessoas, e sim de capitais. Para o autor, o Estado sempre serviu aos interesses financeiros, e só por meio de sua intervenção é que as corporações econômicas logram sucesso nos seus investimentos, em diferentes países. Assim, o sistema interestados, em que a soberania estatal serviria de garantia de segurança e de monopolização aos capitalistas, é algo muito conveniente aos grupos financeiros.

\begin{abstract}
Uma economia-mundo capitalista requer uma estrutura em que haja estados soberanos ligados num sistema interestados. Estes estados desempenham um papel crucial de apoios aos empresários, os principais são assunção de uma parte dos custos de produção, a garantia de quase monopólios para aumentar os coeficientes de lucro, e seu esforço tanto para restringir a capacidade das classes trabalhadoras de defender seus interesses, como para mitigar o descontentamento através de redistribuições parciais da mais-valia (WALLERSTEIN, 2002, p. 109).
\end{abstract}

A relação entre Estado e corporações financeiras é explicada por Bauman e Bordoni (2016) pelo par complementar de poder-política. Para os autores, o Estado já concentrou em maior medida os dois conceitos, mas ultimamente tem perdido cada vez mais espaço de poder para as instituições financeiras, as quais têm utilizado seu poder para pautar as decisões políticas no âmbito do Estado. Desse modo, os governos nacionais estariam perdendo sua soberania pela cisão entre poder e política.

Essa perspectiva aproxima a análise desses autores da visão trazida por Arrighi, o qual comenta que o poder dos mercados globais solapa a governança até de nações como os Estados Unidos (que apresentam dificuldades para controlar até mesmo as corporações surgidas em seu território) e comprometem a eficácia da política exterior e, logo, da hegemonia desse país sobre os outros. Agências privadas de avaliação de crédito parecem exercer influência comparável a de uma potência militar ao baixar os títulos de países. No entanto, Arrighi afirma que não há consenso de que as transformações recentes da globalização de fato restrinjam a atividade dos Estados. A capacidade de controle (militar) que a Grã-Bretanha tinha (no século XIX) de coagir governos a aceitarem determinadas demandas de empresas e capitais estrangeiros hegemônicos é a mesma representada hoje por grandes corporações a agências de crédito como a Moody's. Talvez os 
estados continuem tendo possibilidade de movimento e ação apesar das pressões do mercado global, mas a forma de coação é menos visível e mais efetiva. No caso de os estados não "colaborarem", a crise econômica pode chegar até eles pelo rebaixamento da sua nota pela Moody's e pelo temor da "fuga de capitais".

Diferente da forma como Bauman e Bordoni (2016) abordam a relação entre Estado e mercado, para Wallerstein, o Estado não perdeu sua soberania relativa às movimentações financeiras porque esteve ligado a tais movimentações e interesses capitalistas desde as incursões de companhias de mercadores no mundo além da Europa, as quais eram, muitas vezes, financiadas pelos governos dos países. Para o autor, a fórmula do mercado livre hipotético não consiste em retirar o poder do Estado, e sim na insistência de que este funcione como um "guarda-noturno":

Sua função é se precaver contra intrusos que pretendam roubar a propriedade. E ele o faz, principalmente, apenas por estar lá. Eis que aqui chegamos ao básico, a demanda universalmente observada de proteger o direito à propriedade. Não há sentido em acumular capital se não se puder conservá-lo (WALLERSTEIN, 2002, p. 97).

São os estados os responsáveis pela conservação dos monopólios, agindo junto dos grupos financeiros e não contra eles. Para além das restrições a novos concorrentes, dos incentivos a determinados grupos e do fato de dirigir certas formas de consumo, o papel do estado está também muito claro na manutenção da ordem e na contenção dos anseios das "classes perigosas". Conforme o autor, o principal sentido da manutenção da ordem no estado é precaver-se contra a insurgência dos trabalhadores, o que se leva a cabo através de um misto de políticas voltadas à força e à ilusão pelas concessões (WALLERSTEIN, 2002, p. 100). Além de controlar as insurgências para estar de acordo com as demandas financeiras, essa fórmula também logra a legitimação do governo através da adoção de um pacote de cidadania ou soberania popular mediada. Esse pacote de cidadania implantado pelos governos liberais da Europa no século XIX, e recentemente implantado nas nações periféricas através da fórmula da soberania nacional, manteve-se até meados da década de 1960.

A autodeterminação das nações criou poucos problemas. Mas a redistribuição no âmbito mundial, mesmo que a níveis modestos, ameaçava pôr uma enorme pressão sobre a possibilidade de acumulação incessante de capital. A partir dos anos 70, o liberalismo global já não parecia mais viável (WALLERSTEIN, 2002, 104).

Nesse sentido, a análise de Wallerstein se cruza com a perspectiva de Arrighi (2001) sobre caos sistêmico. A expansão sistêmica do modo de vida hegemônico desenvolveu uma esperança nas soluções do estado para a melhoria de vida das classes populares. Ao expandir sua fórmula sistêmica de modelo de nação, o sistema criou sua própria contradição, a qual vem se desenvolvendo desde a década de 1970. A fórmula 
de conceder alguns direitos sociais às classes populares europeias em troca de legitimidade e ordem não suportaria sua importação para os países periféricos sem uma diminuição drástica dos lucros capitalistas centrais. A frustração dessas esperanças de direitos nos países periféricos levou ao abandono das soluções estatais e, de certa forma, a uma hostilidade ao estado muito visível no contexto brasileiro recente. Além disso, quando as concessões do Estado-de-bem-estar não são possíveis, a fórmula para a contenção das "classes perigosas" e manutenção da ordem passa a ser o estado mínimo para direitos sociais, mas máximo para a penalização da pobreza:

O estado keynesiano, que foi veículo histórico da solidariedade e cuja missão era fazer frente aos ciclos e aos efeitos danosos do mercado, garantindo o bem-estar e a redução das desigualdades, é sucedido por um Estado darwinista que transforma a competição em fetiche e celebra a irresponsabilidade individual (cuja contrapartida é a irresponsabilidade social), recolhendo-se às suas funções soberanas de lei e ordem, elas mesmas hipertrofiadas" (WACQUANT, 2008, p. 97).

Prensados entre a diminuição dos direitos sociais, a violência das formas estatais e privadas de segurança e a constante ameaça da crise do trabalho, os indivíduos das classes trabalhadoras, nas últimas décadas, enxergam o fenômeno da migração como mais uma "pedra no sapato", entendendo que os migrantes alargam a soma de pessoas que podem dividir os direitos produzidos pelos parcos lucros que sobram dos investimentos capitalistas do estado e ainda disputam com as classes mais baixas os subempregos.

Além do problema de disputa cultural que as diferenças étnicas posicionam frente a frente no fenômeno da migração, o enfraquecimento do Estado, ou melhor, a atitude titubeante do mesmo em reafirmar os direitos básicos aos integrantes das populações nacionais lança sobre estes um medo intenso de que o Estado-nação, ao proteger os imigrantes, descuide dos cidadãos ou que, ao promover o alargamento da cidadania aos imigrantes, torne ainda menor a "fatia do bolo5" a ser dividida entre os trabalhadores. No entanto, tanto a notável descrença popular na soberania do Estado quanto o fenômeno da crise migratória parecem ser coadjuvantes e, ao mesmo tempo, efeitos da crise que sobreveio ao último ciclo hegemônico. Dessa forma, essas duas estruturas vão ter que conviver até que a nova governança se estabeleça regulando os fluxos e o papel de cada bloco de estados dentro do sistema-mundo, ou esperar que "o fim concebido" para esse sistema traga novas possibilidades de convívio que integrem os indivíduos, excedendo a lógica do "dentro ou fora" do estado. ${ }^{5}$ Referente à forma como Wallerstein (2002) define a pequena parte de lucros do trabalho que é utilizada pelo Estado para a promoção
de direitos sociais. 


\section{A QUESTÃO MIGRATÓRIA E AS PERSPECTIVAS EM RELAÇÃO AO ESTADO-NAÇÃO}

A tese de que a globalização e a crise recente têm enfraquecido o estado é relativizada nas observações de Arrighi sobre os trabalhos de Wallerstein, para quem a redistribuição dos lucros do trabalho para os capitalistas é obra do manejo estatal das relações financeiras no seu interior. Para autores como Baumam e Bordoni (2016), na globalização, o poder do Estado se vê minado pelo poderio de instituições econômicas transnacionais e a instabilidade dos direitos sociais e das condições favoráveis de trabalho se dá em decorrência disso.

Já para Wallerstein (2002), a relação entre estado e capital é a mesma desde a organização do atual sistema-mundo. O Estado, em termos de governo, não está estremecido pela pressão dos capitalistas na globalização, mas pela descrença popular na soberania e nas soluções centradas na esfera estatal. Mesmo atuando em acordo com as instituições financeiras, a inevitável volatilidade geográfica dos capitais, própria da expansão sistêmica, leva a uma competição por trabalho e, por consequência, a um golpe nos direitos dos trabalhadores, o que também está associado às restrições na capacidade do estado de garantir direitos aos cidadãos.

Para Tilly, citado por Arrighi (2001, p. 20), o declínio dos estados ameaça todos os direitos democráticos porque estes estão fundamentados no Estado-nação. Embora a proposição de Tilly coloque o Estado em uma posição de liderança na produção dos direitos sociais (desconsiderando a resistência dos trabalhadores), a perda do controle dos estados pode representar uma chave para encontrar um fio de esperança na questão da imigração. Se a análise de Tilly acerta minimamente sobre a produção de direitos a partir do estado, no momento em que direitos passam a ser vistos "fora do estado" e, portanto, da cidadania restrita a uma pertença nacional, os imigrantes talvez tenham direitos reconhecidos e sejam menos explorados em termos de trabalho.

Já Bauman e Bordoni (2016) veem nos movimentos do crescente precariado uma forma de organização política diferente do Estado-nação. Porém, quanto aos chamados "movimentos de indignação", embora denotem uma centelha positiva de reorganização popular, há que se atentar para o fato de que movimentos de indignação facilmente podem descambar em ódio a outros indivíduos tidos como rivais ou concorrentes, como os imigrantes, isto é, como medida de proteção dos direitos e cidadania, alguns movimentos nacionais de trabalhadores tendem a ver em setores do próprio precariado o declínio das suas condições de vida. Além disso, tendem a postular, novamente, a cidadania com base na territorialidade do Estado-nação.

A recriação da democracia e a afirmação de direitos parece necessitar de movimentos transnacionais capazes de lidar com os interesses e a necessidade de estabelecer concessões e barganhas com o capital transnacional. O chamado ambiente desfavorável ao trabalho também aparece como produto do 
enfraquecimento da classe trabalhadora na era pós-industrial, e não somente como produto da perda de soberania do estado para instituições financeiras. No entanto, em termos de países periféricos, é mais plausível pensar na reestruturação geográfica da classe trabalhadora pela mudança do mapa industrial para os países antes consumidores ou fornecedores de matéria-prima, o que se relaciona também de maneira íntima com a imigração voltada para a busca de emprego. Toda essa nova cartografia da classe trabalhadora, já identificada por Wallerstein, suscita uma nova interpretação de onde podem emanar os novos direitos sociais a serem construídos. Além disso, Wallerstein aponta para uma "racialização" dos trabalhadores, mesmo nos países ocidentais. É justamente a falta de consenso sobre o que viria a acontecer com o poder mundial e com os estados-nação que anima Arrighi (2001, p. 30-31) a identificar que, nessa crise como mudança sistêmica, há "um processo de reorganização radical do moderno sistema mundial que altera substantivamente a natureza dos integrantes do sistema, sua maneira de se relacionar uns com os outros, e o modo como o sistema funciona e se reproduz".

Talvez a debilidade do Estado-nação em relação aos processos globais de caráter econômico venha de fato a ameaçar os parcos direitos sociais adquiridos a duras penas pelas classes trabalhadores dentro de um entendimento de cidadania e soberania nacional aos moldes iluministas. Mas, de outra forma, talvez a descrença no Estado como principal balizador dos direitos venha a representar um sopro de esperança para a acomodação de populações migrantes dentro de uma nova lógica de promoção de direitos a se configurar a médio prazo. Dado o fato de que o Estado-nação oferece cidadania dentro do entendimento de uma população padronizada e circunscrita a um território, os imigrantes estando "fora do estado" aparecem como populações sobrantes, sem possibilidade de cidadania e, logo, como potenciais inimigos pelo fato de passarem ao largo do controle das instituições nacionais, também reproduzido e negociado a partir da concessão de direitos.

Para Appadurai (1997), a crise do Estado-nação ocasionada pela globalização está centrada não só na esfera da governabilidade, mas fundamentalmente localizada na noção de territorialidade. Os processos de transnacionalização, entre eles as migrações, levaram a um solapamento das funções do Estado de tutor de um território específico e restrito, bem como tornaram impossível a identificação da soberania segundo uma composição étnica homogênea dentro de um território politicamente estável.

A constituição do Estado-nação pressupõe o isomorfismo entre povo, território e soberania legítima, que se encontra ameaçado pelas formas de circulação de pessoas características do mundo contemporâneo. Tornou-se notável como, no mundo em que vivemos, o movimento humano costuma ser decisivo na vida social, e não algo excepcional (APPADURAl, 1997, p. 35). 
Nesse sentido, os movimentos diaspóricos que marcam a crise sistêmica atual são mais um golpe no modelo westfaliano. Para além do enfraquecimento do estado supostamente causado pelas pressões financeiras ou pela descrença popular na manutenção de direitos, as pressões de movimento humano e os problemas sociais gerados sob um contexto global de incerteza é que colocam o Estado numa posição de instabilidade. A produção de translocalidades, ou seja, lugares em que o Estado-nação não tem controle nem da economia nem dos fluxos humanos, são um exemplo dessa debilidade do modelo westfaliano de soberania.

\begin{abstract}
Muitas cidades estão se tornando translocalidades, substantivamente divorciadas de seus contextos nacionais. Estas cidades dividem-se em dois tipos: os principais centros econômicos tão profundamente envolvidos em comércio, finanças, diplomacia e mídia internacionais que se tornaram ilhas culturais com referências nacionais muito frágeis: Hong-Kong, Vancouver e Bruxelas são exemplos desse tipo de cidade. (APPADURAI, 1997, p. 36).
\end{abstract}

Além disso, mesmo que o Estado-nação incentivasse e buscasse controlar um fluxo de migrações, depois de um determinado tempo, elas adquirem dinâmicas próprias, e as populações diaspóricas tendem a proliferar modos de soberania que se sobrepõem ao estado. Segundo Pries (2016, p108), "hoy en día se estima que entre una décima y una tercera parte de la migración internacional registrada es migración no documentada adicional". Isso significa que essas populações tendem a minar o controle estatal com suas dinâmicas, ao mesmo tempo em que as populações integradas ao Estado-nação estão inseridas em uma tendência de entender o território nacional em uma esfera diferente da pertença étnica. Para Appadurai (1997, p. 49), os constantes fluxos migratórios tornaram a noção de nacionalidade algo dissociado da territorialidade do Estado-nação.

Ao passo que emergem as fissuras entre espaço local, translocal e nacional, o território como base para a lealdade e o sentimento nacional está cada vez mais divorciado do território como lugar da soberania e controle estatal da sociedade civil. Os problemas de jurisdição e lealdade estão cada vez mais desvinculados. Isto não é um bom presságio sobre o futuro do estado-nação na sua forma clássica, na qual os dois são imaginados como coexistentes e sustentando-se mutuamente.

As afiliações translocais, trazidas por Appadurai, como produto das migrações, dos deslocamentos forçados e das trocas culturais da própria globalização, são uma marca das novas dinâmicas que cercam a crise do atual sistema-mundo e tendem a sinalizar uma das contradições que levam o sistema interestados ao colapso. Essas novas identidades, que a princípio parecem ter apenas uma implicação de discussão sobre 
pertença étnica e disputas culturais, podem oferecer uma chave de entendimento sobre a necessidade de se pensar novas formas de cidadania que excedam a territorialidade e a noção de soberania do Estado-Nação.

\section{CONSIDERAÇÕES FINAIS}

Retomando o pensamento de Arrighi, pode-se visualizar a forma como a ruptura sistêmica está intimamente relacionada com a expansão inicial do mesmo sistema, numa reprodução dialética. Todo o centro de um sistema tende a expandir-se impondo às demais regiões suas condições e seus pressupostos sobre uma infinidade de formas de relações, como financeiras. Ao expandir seu modelo de Estado-nação após o pacto de Westfália, a hegemonia ocidental criava sua própria contradição. A forma como o atual sistema capitalista dos interestados tem sobrevivido está com o prazo de validade vencido, como nos alerta Wallerstein (2002). Apesar de não ser uma presa fácil na mão de capitalistas transnacionais, e sim um parceiro dessas mesmas corporações, o Estado tende a ruir por contradições ligadas à soberania popular e às relações de trabalho, bem como por contingências globais que nem mesmo as corporações são capazes de controlar, como os conflitos étnicos e as migrações.

Enquanto a nova governabilidade não se estabelece, os estados-nação tentam reeditar antigos nacionalismos para recuperar uma parte desesperada da crença de seus cidadãos através de medidas de um protecionismo territorial contra a "invasão dos imigrantes". No entanto, essa tendência ao extremismo pode não figurar como o prelúdio de novos tempos de estados-nação fechados sobre si mesmos. Nem as grandes corporações, as quais exercem inegável influência sobre os governos têm interesse nesse desfecho. Lembremos que boa parte delas emprega imigrantes em condição de subcidadania nos países centrais, uma vez que as condições impostas a eles diminuem os custos de produção. A reedição dos nacionalismos vistos em alguns países europeus talvez seja análoga àquelas rápidas e curtas recuperações que as bolsas de valores dos países que estão perdendo hegemonia alcançam quando a crise começa a se desenrolar. Nesse sentido, não são sinais de uma retomada da soberania, mas do encaminhamento para sua efetiva deterioração.

Dentro desse entendimento, nos parece que o cenário desenhado por Arrighi que tem se mostrado possível é aquele que não concentra a governabilidade no domínio de um só Estado, mas em um conjunto deles localizados em diferentes regiões, retornando a um equilíbrio do poder político-econômico, como se dava na Antiguidade. Essa possibilidade é vista pelo autor como a fórmula que poderia trazer no seu cerne uma diminuição das desigualdades, justamente por reorganizar o poder em várias zonas de influência, refazendo o mapa do sistema-mundo e estremecendo a atual divisão entre centro e periferia. Além disso, a direção da nova governabilidade, necessariamente, deve levar em consideração a condição de instabilidade 
que se instaurou sobre o domínio e a soberania do Estado-nacional em termos de territorialidade. Uma governabilidade centrada em apenas um Estado ou região hegemônica, quando as populações, culturas e corporações financeiras estão tão implicadas em um constante fluxo, aparece como uma incoerência. Nesse sentido, a garantia de direitos que considere as muitas e crescentes populações em trânsito depende de uma formulação de cidadania que exceda as estruturas institucionais do Estado. Como sugere a proposição de García-Canclini (2008, p. 37), é necessário

[...] que os acordos de livre-comércio sejam acompanhados por regras que ordenem e fortaleçam o espaço público transnacional. Um dos requisitos para isso é que, ademais, globalizemos os direitos cidadãos, que as hibridações multinacionais derivadas de migrações em massa sejam reconhecidas em uma concepção mais aberta de cidadania, capaz de abranger múltiplas pertenças.

Enquanto o Estado-nação for essa unidade aberta para finanças e fechada para direitos, as populações migrantes estarão em condições sub-humanas e a consequente produção do caos e dos desequilíbrios nas estruturas de trabalho serão constantes. Cabe pensar outras formas de produção de direitos para além do Estado que sejam capazes de lidar com a instabilidade de contingências geradas fora do mesmo. Para Markoff (apud ARRIGHI, 2001, p. 21), a crise demonstra que o desafio advindo de "recriar uma democracia só pode ser enfrentado pela organização de movimentos democráticos transnacionais capazes de arrancar 'concessões dos novos donos do poder transnacional"'. Logo, se os processos de desestabilização de direitos são produzidos global ou transnacionalmente, a possibilidade de manutenção e alargamento dos direitos sociais parece que tende a ser produzida também transnacionalmente, talvez através de uma nova forma de organização dos trabalhadores. A forma como a União Europeia tem tentado resolver problemas globais revela uma possibilidade de pensar uma cooperação transnacional e, ao mesmo tempo, local, que ofereça, por exemplo, subsídios para uma cooperação pan-americana.

Talvez essa crise que se alonga desde a década de 1970 não leve com ela a soberania dos Estados-nação como consequência da ruptura sistêmica. Entretando, uma questão parece ser pertinente: se o Estado-nação não reformular suas formas de relacionar-se tanto com poderes financeiros quanto com suas estruturas internas de produção de cidadania (a partir de novas configurações étnicas e territoriais), a semi-soberania dessa instituição, que já completa meio milênio, tende a tornar a vida da maior parcela da população mundial algo insuportável. Para além da prevalência do caos, vale fazer o esforço de pensar que a crise desse sistema que dividiu a comunidade humana em blocos territoriais estanques e desiguais tenda a possibilitar um futuro onde o imaginário da nação dê lugar a comunidades imaginadas maiores (continentais ou globais) ou menores (locais), favorecendo outra compreensão dos valores universais e trazendo os trabalhadores do 
mundo para a aurora de um outro modelo de democracia, numa era de direitos pós-iluministas e de fato universalizáveis.

\section{REFERÊNCIAS}

ACNUR. Mais de $\mathbf{3 0 0}$ mil refugiados e migrantes cruzaram o Mediterrâneo em 2016. Disponível em: $<$ www.acnur.org/portugues/2016/09/20/mais-de-300-mil-refugiados-e-migrantes-cruzaram-o-mediterraneo-em-2016/>. Acesso em: 05 mai. 2018.

APPADURAI, A. Soberania sem territorialidade: Notas para uma geografia pós-nacional. Novos Estudos, n. 49, 1997.

ARRIGHI, G.; SILVER, B,J. Caos e governabilidade no moderno sistema mundial. Rio de Janeiro: UFRJ-Contraponto, 2001.

ARRIGHI, G. O Longo Século XX: dinheiro, poder e as origens de nosso tempo. UNESP, Rio de Janeiro, 1995. BAUMAN, Zygmunt; BORDONI, Carlo. Estado de Crise. Rio de Janeiro, Zahar, 2016.

BEAUD, M. História do capitalismo: de 1500 aos nossos dias. São Paulo: Brasiliense, 1987.

BRAUDEL, F. Histoire et Sciences sociales: La longue durée. Économies, Sociétés, Civilisations. Annales... 13 a., n. 4, 1958, p. 725-753.

BRAUDEL, F. O Mediterrâneo e o mundo Mediterrânico na Época de Filipe II - Vol. I. Tradução Ministério da Cultura Francês. Lisboa: Publicações Dom Quixote, 1983.

GARCÍA-CANCLINI, N. Culturas híbridas: estratégias para entrar e sair da modernidade. 4. ed. São Paulo: Editora da Universidade de São Paulo, 2008.

PRIES, L. Nuevas dinámicas de la migración internacional: retos y oportunidades. In: BESSERER, Federico (Org.). Intersecciones urbanas: Ciudad transnacional: Ciudad global México : Universidad Autónoma Metropolitana- Unidad Iztapalapa : Juan Pablos Editor, 2016.

WALLERSTEIN, I. Estados? Soberania? Os dilemas dos capitalistas numa era de transição. In: WALLERSTEIN, Immanuel. O fim do mundo como o concebemos: Ciência Social para o século XXI. Rio de Janeiro: Editora Revan, 2002.

WACQUANT, L. As duas faces do gueto. São Paulo: Boitempo, 2008. 